\title{
The prevalence of dentofacial anomalies and the prognosis of morbidity of the population living in the zone of ecological distress of the Republic of Dagestan
}

\author{
Tamara F. Kosyreva ${ }^{1}$, Farida I. Astarkhanova ${ }^{1}$, Ibragim R. Astarkhanov', \\ Tamara S. Astarkhanova ${ }^{3}$, Leyla I. Alibalaeva ${ }^{4, *}$, and Ilyas N. Osmanov ${ }^{5}$ \\ ${ }^{1}$ Peoples' Friendship University of Russia, Department Pediatric dentistry and Orthodontics, 117198, \\ Moscow Miklukho-Maklaya str.6, Russian Federation \\ ${ }^{2}$ Dagestan State Agrarian University, Department of Ecology and Plant Protection, 367032, Republic \\ of Dagestan, Makhachkala, M. Gadzhieva str., 180, Russian Federation \\ ${ }^{3}$ Peoples' Friendship University of Russia, Faculty of agriculture and technology, 117198, Moscow \\ Miklukho-Maklaya str.6, Russian Federation a \\ ${ }^{3}$ Peoples' Friendship University of Russia, Department of Agrobiology, 117198, Moscow \\ Miklukho-Maklaya str.6, Russian Federation \\ ${ }^{4}$ Plekhanov Russian University of Economics, Department on Informatics, 117997, Moscow \\ Stremyanny lane, 36, Russian Federation \\ ${ }^{5}$ Dentol, 104469, Moscow Bratislavskaya str, 26, Russian Federation
}

\begin{abstract}
Studies on pesticide load were carried out. The number and the classes of toxic chemicals used in the republic and their ranking by hazard class and toxicological stress are given. Pesticide-contaminated zones of Dagestan were identified. The dependence of the prevalence of dentofacial anomalies and the prognosis of the incidence of the population living in the zones of environmental trouble have been revealed.
\end{abstract}

\section{The relevance of research}

For the most part, the increase in the incidence of dentofacial anomalies is due to the effects of harmful factors found in the air, drinking water, and soil, as well as due to hereditary factors. Experts from the International Cancer Research Agency found that in 75-80\% of cases, environmental factors of a chemical nature play a role in the origin of this disease. The results of research scientists [14-16] indicate an increasing tendency of the prevalence of dentofacial anomalies within the population of Russia and abroad. The analysis of the development and prevalence of dentofacial anomalies is necessary for the development of integrated prevention approaches adapted to the needs of the population of a particular region. The study of the prevalence and risk factors of dentofacial anomalies among the population of the Republic of Dagestan, a region with adverse environmental factors

\footnotetext{
*Corresponding author: alibalaeva.li@ rea.ru
} 
associated with an increased toxicological capacity of pesticides used in the production of vegetables, has not been conducted. According to the literature, there are some individual works dedicated to the study of the frequency of dentofacial anomalies and their structures in children living in these areas. According to the results of studies conducted in 2012, the frequency of dentofacial anomalies in children aged 3 to 14 years was more than $50 \%$ [ 15 , 16]. Thus, the foregoing has predetermined the relevance of this study and served as the basis for its conduct. The difference in frequency of dentofacial anomalies in children according to different authors [13, 17] can be explained by the lack of a unified classification of dentofacial anomalies, the regional particularities of the spreading of pathology, the difference in indicators of dental caries infestations, and the following environmental factors: mineral water, fluorine, arsenic and the degree of the pollution of the environment, etc. According to researchers [4-7], changes in children's bodies living in areas with unfavorable environmental conditions, evidence the state of their health and influence the development and formation of dental morbidity. It has been established that environmental pollution leads to a deterioration in the health of the children's population and an increase in dental morbidity $[2,3,14,15]$.

As a result of chemical effects on the body, a decrease in the protective mechanisms, and a decrease in the balance of oxidative processes in the oral cavity and oral fluid take place; the intensity of anaerobic oxidation increases. Thus, conditions for the development of dental pathology are created. Consequently, environmental factors affect the hard tissues of the teeth indirectly, including through the changing properties and composition of saliva. According to R.G. Turaev (1998), the highest levels of dentofacial anomalies are found among children living in the most environmentally disadvantaged areas of cities: Dental anomalies occurred in up to $42.1 \%$ of still developing bodies and up to $57.9 \%$ occurred in already developed bodies, whereas dental anomalies occurred in only 15.6 and $23.1 \%$ of those living in relatively "clean" areas. Numerous studies of domestic and foreign authors have proved the importance of microelement compositions and drinking water in the development of hard tissue pathology of both temporary and permanent teeth, which, in turn, is associated with the geochemical characteristics of the area of residence [1-4, 13-15].

The author's data [13] indicates that there is a direct connection between the insufficient content of the chemical compound of fluorine in drinking water and the formation of dental caries, and, what is more, the lower the fluorine concentration, the greater the prevalence and intensity of caries. There are works containing conflicting data on the frequency of dental-maxillary anomalies in children and adolescents consuming water with different fluorine contents $[7,13,14,16]$ although, statistics on the beneficial effects of optimal doses of fluoride on the general condition of the body are well known. Fluorine is a trace element that directly affects the structure of the teeth and bones $[5,7]$. The selective quality of fluorine makes causes to think about the significance of this element in the etiology and pathogenesis of dentofacial anomalies, which have not yet been studied sufficiently. Determining the degree of the possible influence of fluoride in drinking water on the development of pathology in the dental system was the goal of a number of studies [14-16]. The authors studied the prevalence of anomalies of the teeth, dentition and occlusion in areas with different fluoride levels in drinking water. It has been established that the prevalence of anomalies of individual teeth does not change significantly depending on the fluorine content. Dentition anomalies are more often observed in children consuming water with an insufficient fluorine content, occlusion anomalies are less common in areas with an optimal content of this trace element and significantly more common in areas with a high fluorine content. The author's research [15] noted an increase in the prevalence of a deep bite in children living in areas with a high content of this trace element. Some authors have found that dental anomalies and deformities are more common 
in children who consume water with a low fluorine content than with optimal and elevated concentrations [14-16].

\section{Objective}

To identify the prevalence of dentofacial and maxillary anomalies on the basis of toxicological stress as one of the environmental risk factors, and to predict the incidence of the population living in the Republic of Dagestan.

\section{Study objectives}

- calculate the toxicological stress of pesticides using years of research;

- study the prevalence of dentofacial anomalies in the Republic of Dagestan;

- establish a correlation between the toxicological stress and the prevalence of dentofacial anomalies in the Republic of Dagestan;

- study the epidemiology of dentofacial anomalies in children at different periods of the formation of the dental system, taking into account the ecological characteristics of the areas of residence and determine the factors of their development (for example, in the city of Makhachkala).

\section{Scientific novelty}

For the first time, the dependence of dentofacial anomalies on toxicological stress has been studied as one of the environmental risk factors, an ecotoxicological map and a forecast of the incidence of DFA in different zones have been drawn up, the role of risk factors in the development of dentofacial anomalies has been evaluated.

\section{Research results}

Many chemical elements that cause dentofacial anomalies and other diseases are part of the pesticides and agrochemicals used in the production of agricultural products consumed fresh by the population. They lead to a number of negative consequences, such as contamination of agricultural products and soils with toxic substances that penetrate through the groundwater and into the drinking water [6, 7, 9-11]. The main portion of the total amount of pesticides used is made up of fungicides (ued against plant diseases), followed by insecticides (used against pests), acaricides (used against ticks), herbicides (used against weeds) and rodenticides (used against rodents) (Table 1).

Table 1. The number of pesticides used in the Republic of Dagestan (2017 in tons).

\begin{tabular}{|c|c|c|}
\hline Name of pesticide & Received in a year & Used in a year \\
\hline Insectoacaricides & 100.0 & 118.0 \\
\hline Rodenticides & 1.7 & 1.7 \\
\hline Fungicides & 308.1 & 314.5 \\
\hline Herbicides & 55.6 & 60.9 \\
\hline In Total: Top & 465.4 & 489.8 \\
\hline
\end{tabular}

In scientific literature, which broadly focuses mostly on the effects of pesticidal loads on the health of the population. The role of individual groups of chemical compounds of pesticides and mineral fertilizers, differing in toxicity, durability and cumulativeness, in changing incidence rates is not sufficiently represented [4, 5]. Over 400 tons of pesticides are consumed annually in the republic. The assortment of pesticides and chemical compounds was analyzed and pesticide loads, the assortment index of pesticides, their residual content in food products and environmental objects were calculated on the territories of various zones of the republic [6-8]. The corresponding figures for pesticides 
were previously obtained for the 20-year-period of 1990-2010 by other researchers, and our task was to determine whether the situation had changed 10 years later. The analysis showed that since 2010, the intensity of pesticide use has decreased significantly. So, in 2018 , the pesticide load (PN) was $15.5 \%$ of the 2010 value, which we associate with the use of new drugs with low consumption rates. The total pesticide load in the administrative territories of Dagestan ranged from $9.7 \mathrm{~kg} / \mathrm{ha}$ in 2010 to $5.15 \mathrm{~kg} / \mathrm{ha}$ in 2018 . In total, in the regions of Dagestan, pesticides of 10 groups of chemical compounds are used, including more than 30 preparative forms (Fig. 1).

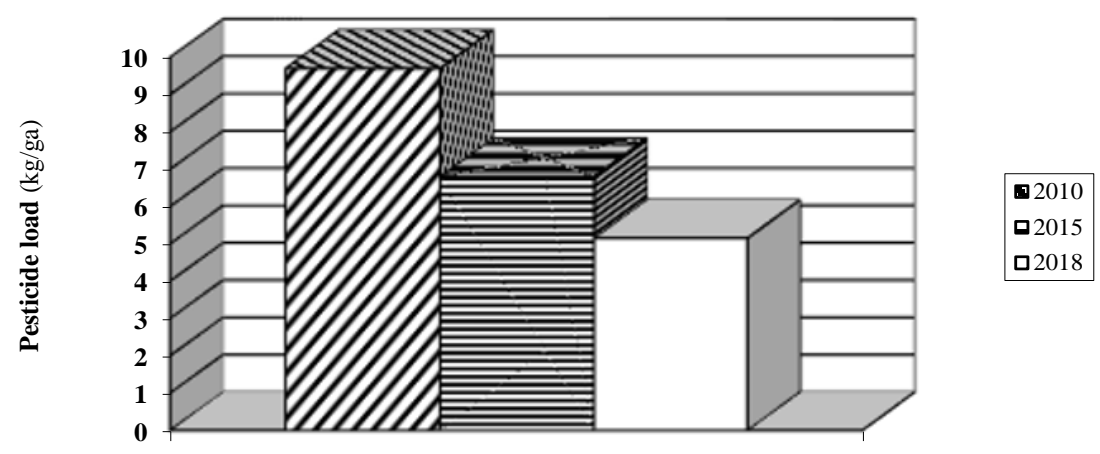

Fig. 1. Pesticide load on agricultural crops in Dagestan (2010-2018).

The pesticide load of the drug was determined by the traditional method, dividing the mass of the drug by the active substance on the entire area of agricultural land of all categories. If you determine the pesticide load of a certain drug at the rate of only the area on which a certain crop is grown, during the production of which a particular pesticide is used, the value of this indicator rises significantly. Pesticide load is a sufficient criterion for the intensity of pesticide use in the territory. When grouping pesticides used in the plain zone by oral toxicity according to the pesticide hygiene classifier by hazard level, it was noted that $0.001 \%$ of the total pesticide load was extremely dangerous, $2.9 \%$ dangerous, $34.6 \%$ moderately dangerous and $62.5 \%$ were low-hazard pesticides. Thus, about $3.0 \%$ of the total pesticidal load in the Republic of Dagestan made up 1 and 2 hazard classes, $97 \%-3$ and 4 hazard classes (Fig. 2).

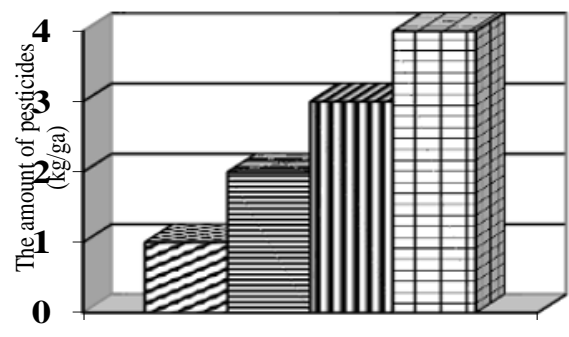

\begin{tabular}{|l|}
\hline $\mathbf{D}$ Extremely dangerous \\
$\boldsymbol{\Xi}$ Dangerous \\
$\mathbf{0}$ Moderately Dangerous \\
$\boldsymbol{\theta}$ Less dangerous \\
\hline
\end{tabular}

Fig. 2. Territorial load of pesticides by degree of danger (2010-2018). 
We have found that a large degree of environmental pollution has been established on the territory of the plain zone of Dagestan and is associated with a high intensity of chemical treatments on agricultural crops that produce food; the treatments can be as frequent as 20 times per season. Next, the territory is ranked and divided into foothill and mountain land. On the basis of the conducted research, an ecotoxicological map of Dagestan was compiled with the release of contaminated zones (Fig. 3). The comparison of incidence rates of dental anomalies (Table 2) with the pesticidal load showed that it is higher in the lowland zone, which correlates with our data on pesticidal load.

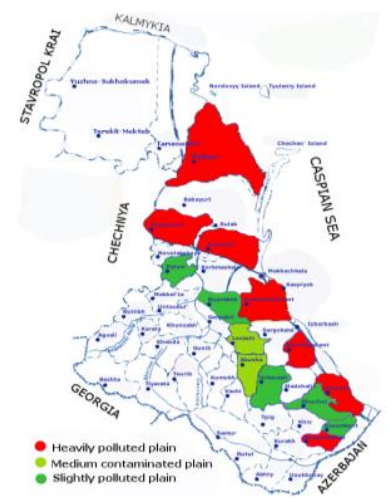

Fig. 3. Ranking of the territory by toxicological load on the example of the Republic of Dagestan.

Table 2. Average long-term indicators of dental diseases in various age groups of the population of Dagestan in the period of 2010 to 2018 ( $\%$ of the total).

\begin{tabular}{|c|c|c|}
\hline Age (years) & Foothill zone & Plain zone \\
\hline $0-5$ & 10.8 & 12.9 \\
\hline $6-10$ & 20.0 & 10.0 \\
\hline $11-15$ & 10.9 & 11.7 \\
\hline $16-20$ & 10.0 & 12.0 \\
\hline $21-25$ & 11.2 & 30.0 \\
\hline $26-30$ & 22.5 & 8.9 \\
\hline
\end{tabular}

To identify the correlation between dental-maxillary anomalies and toxic load, we analyzed the prevalence of dentofacial anomalies among children and adolescents in the city of Makhachkala. The city of Makhachkala is the capital of the republic, which has a population of 596,356 thousand. More than 30 percent of the population are children and adolescents. Makhachkala is considered a city unfavorable in terms of ecology, due to the 500 brick factories located within a $2 \mathrm{~km}$ radius of the city, that use open methods of brick burning, which adversely affects the environment, in particular, pollutes the atmosphere and destroys the fertile soil layer. The composition of the dust released during the production of bricks includes components similar in composition to those of pesticides. We conducted a survey of 100 children in the kindergartens and schools of Makhachkala. The parents of a contingent of children of 3-5 years old were surveyed while the students, themselves, were surveyed among the other age groups.

According to the results of the data analysis, it turned out that the prevalence of dental anomalies among children and adolescents in the city ranges from $35.0 \%$ among adolescents and to $59.0 \%$ among children aged 3-5 years. The lowest frequency of dentofacial anomalies is common for the baby teeth occlusion period $-40.5 \%$. By $10-15$ years, there is a decrease in the frequency of dentofacial anomalies to $41 \%$, which 
can be explained by the ability of self-regulation of anomalies in the permanent teeth period. Children and adolescents with anomalies out of the total number of identified diseases accounted for more than 50\% (Table 4). Occlusion anomalies were found in 59\% of preschool aged children. The frequency of occlusion anomalies decreases with the growth and development of children, and during the permanent occlusion period, at the age of $10-15$ years, it is $48 \%$. In the process of self-regulation, occlusion is normalized in almost $40.0 \%$ of cases. The most common type of jaw anomaly in all age periods were deep bite anomalies, their frequency being $20.0 \%$.

Table 4. The prevalence of anomalies of dentition among children and adolescents of the city of Makhachkala.

\begin{tabular}{|c|c|c|c|c|c|c|c|c|c|}
\hline \multirow{2}{*}{$\begin{array}{c}\text { Age } \\
\text { (years) }\end{array}$} & $\begin{array}{c}\text { Number } \\
\text { of } \\
\text { examined } \\
\text { persons }\end{array}$ & $\begin{array}{c}\text { Number } \\
\text { of } \\
\text { patients }\end{array}$ & $\begin{array}{c}\text { Progn } \\
\text {-athic }\end{array}$ & $\begin{array}{c}\text { Proge } \\
\text {-nesis }\end{array}$ & $\begin{array}{c}\text { Overbit } \\
\text { e }\end{array}$ & $\begin{array}{c}\text { Open } \\
\text { bite }\end{array}$ & $\begin{array}{c}\text { Cross } \\
\text { bite }\end{array}$ & $\begin{array}{c}\text { Combined } \\
\text { anomalies }\end{array}$ & Total \\
\hline $3-5$ & 10.8 & 12.9 & 20 & 2 & 30 & 3 & 2 & 2 & 59 \\
\hline $6-10$ & 20.0 & 10.0 & 25 & 6 & 20 & 3 & 5 & 3 & 61 \\
\hline $10-15$ & 10.9 & 11.7 & 18 & 5 & 14 & 1 & 1 & 2 & 41 \\
\hline $15-20$ & 10.0 & 12.0 & 4 & 4 & 6 & 1 & 1 & 9 & 23 \\
\hline
\end{tabular}

The paper was financially supported by the Ministry of Education and Science of the Russian Federation on the program to improve the competitiveness of RUDN University among the world's leading research and education centres in the 2016-2020.

\section{References}

1. S. V. Averyanov, S. V. Chuykin, O. S. Chuykin, A. V. Zubareva, Actual Problems of the Humanities and Natural Sciences 6, 57-61 (2015)

2. S. V. Averyanov, O. S. Chuykin, Dental Forum 2, 28-32 (2009)

3. Z. K. Amirova, E. A. Kruglov, Dioxin damage cohorts, effects of the production of phenoxy herbicides and 2,3,7,8- TCDD in Ufa (Dioxins: environmental problems and methods of analysis: mater. conf.. Part II, 51-55, 1995)

4. T. S. Astarkhanov, Ecotoxicological substantiation of the optimization of the use of chemical plant protection products in systems for the protection of perennial plantations against pests and diseases in the North Caucasus region (Abstract for the degree of Doctor of Agricultural Sciences, St. Petersburg, 2008)

5. T. I. Abasova, T. S. Astarkhanova, The circulation of pesticides in the biosphere and their ecotoxicological assessment (The third All-Russian scientific-practical conf "Agrotechnical method in plant protection", 68-70, 2005)

6. T. S. Astarkhanova, T. I. Abasova, Environmental contradictions in the use of chemical plant protection products (Third All-Russian Scientific and Practical Conf. "Agrotechnical method in plant protection", 67-68, 2005)

7. I. R. Astarkhanov, Principles of ranking the territory according to the degree of pollution and intensity of the ecological situation (Environmental problems of agriculture and the scientific and practical ways to solve them. Collection of scientific 
papers of the international scientific-practical conference, Makhachkala, 205-215, 2017)

8. T. S. Astarkhanov, Problems of Development of the Agroindustrial Complex of the Region 22, 2, 52-55 (2018)

9. P. I. Gabibova, Ecological-geographical, socio-economic conditionality and prognosis of the incidence of malignant neoplasms in the population of mountainous regions of the Republic of Dagestan (Diss. Ph.D., 2008)

10. A. G. Gasangadzhieva, Ecological and geographical principles for predicting the incidence of malignant neoplasms of the population of the Republic of Dagestan (Diss. PhD., 2010)

11. Annual reports of the Federal Agency Dagestan state station of protection of plants for 1990-2005.

12. Annual reports of Federal state budgetary institution Russian agricultural center for 2005-2019.

13. G. D. Ikromova, The prevalence of dental anomalies among children and adolescents of the republic (Diss. Ph.D., 2007)

14. M. M. Kerimov, Protection of public health in terms of exposure to the unbalanced chemical composition of the waters of the Terka-Kuma artesian basin (Diss. MD, 149, 2004)

15. D. O. Romanov, Prevalence, prevention and treatment of dentition anomalies and deformities in children of the Krasnodar Territory (Diss MD., 2010)

16. A. I. Pronyaeva, The influence of unfavorable environmental factors on the occurrence of the system (Diss Ph.D., 2012)

17. S. M. Shamov, Bulletin of New Medical Technologies 3, 82 (2012) 